\section{REVISTA CIENTÍFICA RURAL}

ISSN: $1413-8263 \quad 2525-6912$
Revista Técnico-Científica

\title{
DESEMPENHO E DIGESTIBILIDADE DE FRANGOS DE CORTE ALIMENTADOS COM QUIRERA DE ARROZ
}

\author{
Suelen Nunes da Silva1 ${ }^{1}$, Berilo de Souza Brum Júnior², Beatriz Simões Valente ${ }^{1}$, Naiana \\ Enhardt Manzke ${ }^{1}$, Débora Cristina Nichelle Lopes ${ }^{1}$, Leomar André Henrich ${ }^{1}$, Fernando Rutz ${ }^{1}$, Eduardo \\ Gonçalves Xavier ${ }^{1}$
}

'Universidade Federal de Pelotas; ${ }^{2}$ Instituto Federal de Educação, Ciência e Tecnologia de Farroupilha - Campus Júlio de Castilhos

RESUMO: O estudo avaliou desempenho e digestibilidade de frangos de corte alimentados com diferentes níveis (0, 20, 40 e 60\%) de quirera de arroz (QA). Utilizaram-se 500 pintos da linhagem Cobb 500. Para determinar o desempenho, 400 aves foram alojadas em boxes contendo cama de maravalha, comedouro tubular e bebedouro tipo nipple. Para avaliação da digestibilidade, 100 frangos foram mantidos em gaiolas metabólicas com comedouro calha, bebedouro tipo nipple e bandeja coletora de excretas. Utilizou-se o delineamento inteiramente casualizado e os dados passaram por análise de variância e regressão polinomial com o auxílio do programa Statistical Package for Social Sciences (SPSS). O ganho de peso apresentou efeito quadrático em todas as semanas, aumentando até o nível de $40 \%$ de QA. O consumo de ração e a conversão alimentar não foram afetados. Verificouse aumento linear da digestibilidade das dietas, da proteína e das cinzas, e efeito quadrático da digestibilidade do extrato etéreo, aumentando após o nível de $40 \%$ de QA. Concluiu-se que a QA pode ser incorporada na dieta de frangos de corte em até $40 \%$ em substituição ao milho, aumentando a digestibilidade e melhorando o ganho de peso.

Palavras-chave: alimento alternativo, desempenho zootécnico, linhagem Cobb.

\section{PERFORMANCE AND DIGESTIBILITY OF BROILERS FED WITH BROKEN RICE}

ABSTRACT: A trial was carried out at the Poultry Farm of the Department of Animal Science of the Federal University of Pelotas to evaluate the performance and digestibility of broilers fed with levels (0, 20, 40 e 60\%) of broken rice (BR). Were used 500 chicks (Cobb 500). For the performance evaluation, 400 birds were allotted to boxes, containing wood shavings, tubular feeder and nipple fountain. For digestibility evaluation, 100 chicks were placed in metabolic metallic cages with trough type feeder, nipple fountain and trail for excreta collection. A completely randomized design was used, and the data were submitted to analysis of variance 
and polynomial regression with the Statistical Package for Social Sciences (SPSS) software. The weight gain showed quadratic response in all the weeks, increasing up to $40 \%$ of BR. Both feed intake and feed per gain ratio were not affected. A linear increase in the digestibility of the diets, protein and ash, and a quadratic effect of the digestibility of the ether extract was observed, increasing after $40 \%$ BR. In conclusion, BR can be added to the broiler diet up to $40 \%$ as a substitute of corn, increasing digestibility and weight gain.

Keywords: alternative feedstuff, Cobb lineage, performance.

\section{INTRODUÇÃO}

Em 2017 o Brasil produziu cerca de 13,05 milhões de toneladas de carne de frango e exportou mais de $33 \%$ desse total, tornando-se o maior exportador mundial (ABPA, 2018). Essa produção é resultado de alguns fatores como o clima, a produção de grãos, o baixo custo com mão-de-obra, além de avanços genéticos, nutricionais e sanitários que tornam o produto competitivo no mercado mundial.

Segundo Rizzo et al 2010, a alimentação de frangos de corte representa em torno de $70 \%$ dos custos totais da produção. Baseado nisso, surge a necessidade de pesquisar alimentos alternativos que atendam às necessidades nutricionais dos animais reduzindo os custos das dietas.

Dentre os alimentos alternativos está a quirera de arroz, que é formada pelos grãos quebrados durante o beneficiamento do arroz (Oryza sativa L.). São produzidos em média $14 \%$ de grãos quebrados nesse processo, o que se torna um problema econômico, tendo em vista que o valor da quirera representa apenas a quinta parte daquele obtido na comercialização do grão inteiro (SILVA E ACHERI, 2009). Porém, este subproduto contém a mesma composição centesimal média do grão inteiro, além de ser uma fonte rica em amido e apresentar valores nutricionais semelhantes ao do milho (ROSTAGNO, 2005; LIMBERGER et al. 2008).

Em regiões grandes produtoras de arroz, como o Estado do Rio Grande do Sul, que é responsável por mais de $71,4 \%$ do total nacional (IBGE, 2017) a quirera de arroz representa um importante alimento que pode ser incorporado em dietas para animais. No entanto, a quirera pode ser encontrada em vários graus de limpeza e apresenta como contaminantes a casca do arroz, sementes de capim-arroz 
(Equinocloa spp) e angiquinho (Aeschinomene spp), que podem corresponder a $6,3 \%$ do volume total colhido no campo (FIALHO et al.2005). Oliveira et al., 2005 já relataram que o consumo de altos níveis de angiquinho pode gerar intoxicação em animais.

O objetivo do presente trabalho foi verificar a influência da utilização de quirera de arroz sobre o desempenho produtivo de frangos de corte e a digestibilidade das dietas contendo esse subproduto do arroz.

\section{MATERIAL E MÉTODOS}

O experimento foi realizado no Aviário Experimental do Departamento de Zootecnia da Faculdade de Agronomia Eliseu Maciel da Universidade Federal de Pelotas. Foi utilizado um total de 500 pintos machos para a realização do trabalho.

Para a avaliação do desempenho produtivo foram utilizados 400 pintos de corte machos da linhagem Cobb, com um dia de idade, distribuídos em um delineamento inteiramente casualizado com quatro tratamentos (0,20, 40 e $60 \%$ de QA) e cinco repetições, com 20 aves cada uma. Os animais foram alojados em boxes com 1,6 $\mathrm{m}^{2}$, contendo cama de maravalha, comedouro tubular e bebedouro tipo nipple.

A pesagem das aves e da ração foi realizada semanalmente para avaliação do ganho de peso, do consumo e da conversão alimentar. As dietas experimentais (Tabelas 1 e 2) foram formuladas para atender às necessidades da categoria de acordo com as recomendações de Rostagno (2005), contendo quatro níveis de quirera de arroz (0, 20, 40 e 60\%) em substituição ao milho.

Para o ensaio de digestibilidade foram utilizados 100 pintos submetidos aos mesmos tratamentos, com cinco repetições de cinco aves e alojados em baterias metálicas com piso de grade, contendo comedouros tipo calha, bebedouros tipo nipple e bandeja coletora de excretas. Foi realizado o método de coleta total de excretas com o auxílio de marcador na ração. As excretas foram coletadas duas vezes ao dia, do $10^{\circ}$ ao $14^{\circ}$ dia, embaladas e congeladas para posterior homogeneização e retirada de amostra para avaliação da composição das mesmas 
conforme a metodologia descrita por Silva; Queiroz (2002). Os dados foram submetidos à análise de variância e de regressão com o auxílio do programa estatístico Statistical Package for Social Sciences (SPSS).

Tabela 1 - Composição das dietas pré-inicial e inicial para frangos de corte contendo níveis de quirera de arroz (QA) de acordo com a fase de desenvolvimento.

Table 1 - Composition of pre starter and starter diets for broilers containing levels of broken rice bran (BR) according to the development phase.

\begin{tabular}{|c|c|c|c|c|c|c|c|c|}
\hline Ingrediente & \multicolumn{4}{|c|}{ Pré-inicial (1 a 7 dias) } & \multicolumn{4}{|c|}{ Inicial (8 a 21 dias) } \\
\hline Quirera de arroz & 0,00 & 20,00 & 40,00 & 58,11 & 0,00 & 20,00 & 40,00 & 56,50 \\
\hline Milho & 57,08 & 37,44 & 17,79 & 0,00 & 62,40 & 40,32 & 18,23 & 0,00 \\
\hline Farelo de soja & 36,14 & 35,29 & 34,45 & 33,69 & 31,33 & 32,64 & 33,95 & 35,02 \\
\hline Fosfato bicálcico & 2,54 & 2,54 & 2,54 & 2,54 & 2,39 & 2,39 & 2,39 & 2,39 \\
\hline Óleo de soja & 1,94 & 2,40 & 2,87 & 3,29 & 1,75 & 2,58 & 3,40 & 4,09 \\
\hline Calcário calcítico & 0,81 & 0,81 & 0,81 & 0,80 & 0,76 & 0,76 & 0,76 & 0,76 \\
\hline Sal comum & 0,56 & 0,56 & 0,56 & 0,56 & 0,54 & 0,54 & 0,54 & 0,54 \\
\hline Suplemento ${ }^{1}$ & 0,50 & 0,50 & 0,50 & 0,50 & 0,50 & 0,50 & 0,50 & 0,50 \\
\hline L-Lisina & 0,22 & 0,24 & 0,26 & 0,28 & 0,16 & 0,16 & 0,15 & 0,14 \\
\hline DL-Metionina & 0,22 & 0,22 & 0,23 & 0,23 & 0,15 & 0,12 & 0,09 & 0,06 \\
\hline \multicolumn{9}{|c|}{ Composição centesimal analisada ${ }^{2}$} \\
\hline Umidade (\%) & 12,12 & 11,73 & 11,89 & 11,95 & 12,32 & 12,23 & 12,38 & 11,9 \\
\hline E. Bruta (Mcal/kg) & 3,92 & 3,93 & 3,89 & 3,89 & 3,85 & 3,95 & 3,99 & 3,94 \\
\hline Proteína Bruta (\%) & 20,48 & 20,27 & 19,24 & 20,58 & 18,89 & 19,06 & 19,35 & 19,83 \\
\hline Extrato Etéreo (\%) & 2,91 & 2,20 & 1,59 & 1,26 & 1,96 & 1,60 & 1,28 & 1,52 \\
\hline Fibra Bruta (\%) & 3,34 & 1,86 & 1,97 & 2,85 & 8,45 & 4,57 & 3,50 & 3,05 \\
\hline Cinzas (\%) & 5,74 & 5,84 & 5,71 & 5,76 & 5,40 & 5,37 & 5,49 & 5,88 \\
\hline
\end{tabular}

${ }^{1}$ Suplemento vitamínico-mineral: quantidade por kg de ração: Vit. A (UI): 12.000; Vit. D3 (UI): 4.500; Vit. E (mg): 24; Vit. K3 (mg): 3; Vit. B1 (mg): 3; Vit. B2 (mg): 8,5; Vit. B12 ( $\mu \mathrm{g})$ : 18; Ác. Fólico (mg): 1,5; Ác. Nicotínico (mg): 32; Ác. Pantotênico (mg): 24; Biotina $(\mu \mathrm{g}):$ 250; Mn (ppm): 90; Zn (ppm): 80; Fe (ppm): 60; Cu (ppm): 12; I (ppb): 900; Se (ppb): 300; Salinomicina (ppm): 600; Bacitracina de zinco (ppm): 60; Olaquindox (mg): 50; Endox (ppm): 80.

${ }^{2}$ Análise realizada no Laboratório de Nutrição Animal (LNA)/DZ/FAEM/UFPEL. 
Tabela 2 - Composição das dietas de crescimento e final para frangos de corte contendo níveis de quirera de arroz (QA) de acordo com a fase de desenvolvimento.

Table 2 - Composition of growth and final diets for broilers containing levels of broken rice bran (BR) according to the development phase.

\begin{tabular}{|c|c|c|c|c|c|c|c|c|}
\hline Ingrediente & \multicolumn{4}{|c|}{ Crescimento (22 a 35 dias) } & \multicolumn{4}{|c|}{ Final (36 a 41 dias) } \\
\hline Quirera de arroz & 0,00 & 20,00 & 40,00 & 56,94 & 0,00 & 20,00 & 40,00 & 60,00 \\
\hline Milho & 60,20 & 38,77 & 17,35 & 0,00 & 64,42 & 42,99 & 21,57 & 0,00 \\
\hline Farelo de soja & 32,13 & 32,84 & 33,56 & 33,47 & 28,08 & 28,79 & 29,51 & 30,22 \\
\hline Fosfato bicálcico & 2,22 & 2,22 & 2,22 & 2,22 & 2,05 & 2,05 & 2,05 & 2,05 \\
\hline Óleo de soja & 3,53 & 4,25 & 4,98 & 5,48 & 3,56 & 4,29 & 5,02 & 5,75 \\
\hline Calcário calcítico & 0,71 & 0,71 & 0,71 & 0,71 & 0,66 & 0,66 & 0,66 & 0,66 \\
\hline Sal comum & 0,52 & 0,52 & 0,52 & 0,52 & 0,50 & 0,50 & 0,50 & 0,50 \\
\hline Suplemento' ${ }^{1}$ & 0,50 & 0,50 & 0,50 & 0,50 & 0,50 & 0,50 & 0,50 & 0,50 \\
\hline L-Lisina & 0,06 & 0,04 & 0,03 & 0,03 & 0,11 & 0,09 & 0,07 & 0,05 \\
\hline \multirow[t]{2}{*}{ DL-Metionina } & 0,14 & 0,14 & 0,13 & 0,13 & 0,14 & 0,13 & 0,13 & 0,12 \\
\hline & \multicolumn{8}{|c|}{ Composição centesimal analisada ${ }^{2}$} \\
\hline Umidade (\%) & 13,47 & 12,89 & 13,31 & 13,77 & 13,46 & 13,56 & 14,01 & 14,32 \\
\hline E. Bruta (Mcal/kg) & 4,09 & 3,71 & 4,10 & 4,06 & 4,07 & 4,11 & 4,14 & 4,00 \\
\hline Proteína Bruta (\%) & 19,70 & 18,42 & 19,43 & 19,07 & 17,09 & 17,28 & 17,14 & 17,62 \\
\hline Extrato Etéreo (\%) & 1,67 & 2,16 & 1,97 & 1,09 & 2,56 & 1,09 & 1,38 & 1,14 \\
\hline Fibra Bruta (\%) & 3,90 & 4,07 & 2,99 & 2,65 & 4,57 & 3,42 & 3,25 & 2,79 \\
\hline Cinzas (\%) & 5,52 & 5,26 & 5,66 & 5,55 & 5,83 & 5,07 & 5,12 & 5,42 \\
\hline
\end{tabular}

${ }^{1}$ Suplemento vitamínico-mineral: quantidade por kg de ração: Vit. A (UI): 12.000; Vit. D3 (UI): 4.500; Vit. E (mg): 24; Vit. K3 (mg): 3; Vit. B1 (mg): 3; Vit. B2 (mg): 8,5; Vit. B12 ( $\mu \mathrm{g})$ : 18; Ác. Fólico (mg): 1,5; Ác. Nicotínico (mg): 32; Ác. Pantotênico (mg): 24; Biotina ( $\mu \mathrm{g})$ : 250; Mn (ppm): 90; Zn (ppm): 80; Fe (ppm): 60; Cu (ppm): 12; I (ppb): 900; Se (ppb): 300; Salinomicina (ppm): 600; Bacitracina de zinco (ppm): 60; Olaquindox (mg): 50; Endox (ppm): 80.

${ }^{2}$ Análise realizada no Laboratório de Nutrição Animal (LNA)/DZ/FAEM/UFPEL.

\section{RESULTADOS}

O consumo de ração e a conversão alimentar não apresentaram diferença significativa entre os tratamentos com diferentes níveis de inclusão da QA. Os resultados obtidos podem ser visualizados na Tabela 3. 
Tabela 3 - Consumo de ração (CR) aos 7, 14, 21, 28 e 35 dias, em gramas, e conversão alimentar (CA) de frangos de corte com sete dias alimentados com dietas contendo diferentes níveis de quirera de arroz.

Table 3 - Feed intake at 7, 14, 21, 28 and 35 days, in grams, and feed conversion of broilers with seven days fed diets containing different levels of rice rice.

\begin{tabular}{ccccccc}
\hline QA, \% & CR-7 & CR-14 & CR-21 & CR-28 & CR-35 & CA \\
\hline 0 & 155 & 557 & 1221 & 2264 & 3379 & 1,27 \\
20 & 156 & 573 & 1226 & 2266 & 3352 & 1,24 \\
40 & 159 & 568 & 1225 & 2223 & 3356 & 1,23 \\
60 & 155 & 546 & 1189 & 2162 & 3225 & 1,20 \\
\hline P & $0,83^{\text {ns }}$ & $0,06^{\mathrm{ns}}$ & $0,25^{\mathrm{ns}}$ & $0,07^{\mathrm{ns}}$ & $0,06^{\mathrm{ns}}$ & $0,25^{\mathrm{ns}}$ \\
CV, \% & 4,70 & 2,30 & 2,49 & 2,74 & 2,61 & 4,32 \\
\hline
\end{tabular}

QA: quirera de arroz; P: probabilidade; CV: coeficiente de variação.

ns: valores não singnificativos no teste de análise de variância a $5 \%$.

O ganho de peso das aves apresentou efeito quadrático durante todo o período experimental, aumentando até o nível de $40 \%$ de QA (Figura 1). Verificou-se um aumento linear significativo na digestibilidade da dieta $\left(y=0,102 x+71,623 ; R^{2}=0,8117\right)$, da proteína $\left(y=0,1239 x+59,846 ; R^{2}=0,9024\right)$ e das cinzas $\left(y=0,1217 x+27,263 ; R^{2}=0,9908\right)$ com o aumento do nível de QA na dieta dos frangos, até 60\% (Figura 2). Já a digestibilidade do extrato etéreo apresentou um comportamento quadrático ( $y=0,0087 x^{2}-0,3056 x+59,846$; $\mathrm{R}^{2}=0,9428$ ), atingindo o ponto mínimo com $17,56 \%$ de $\mathrm{QA}$ e depois aumentando até $60 \%$ de QA na dieta (Figura 2). 

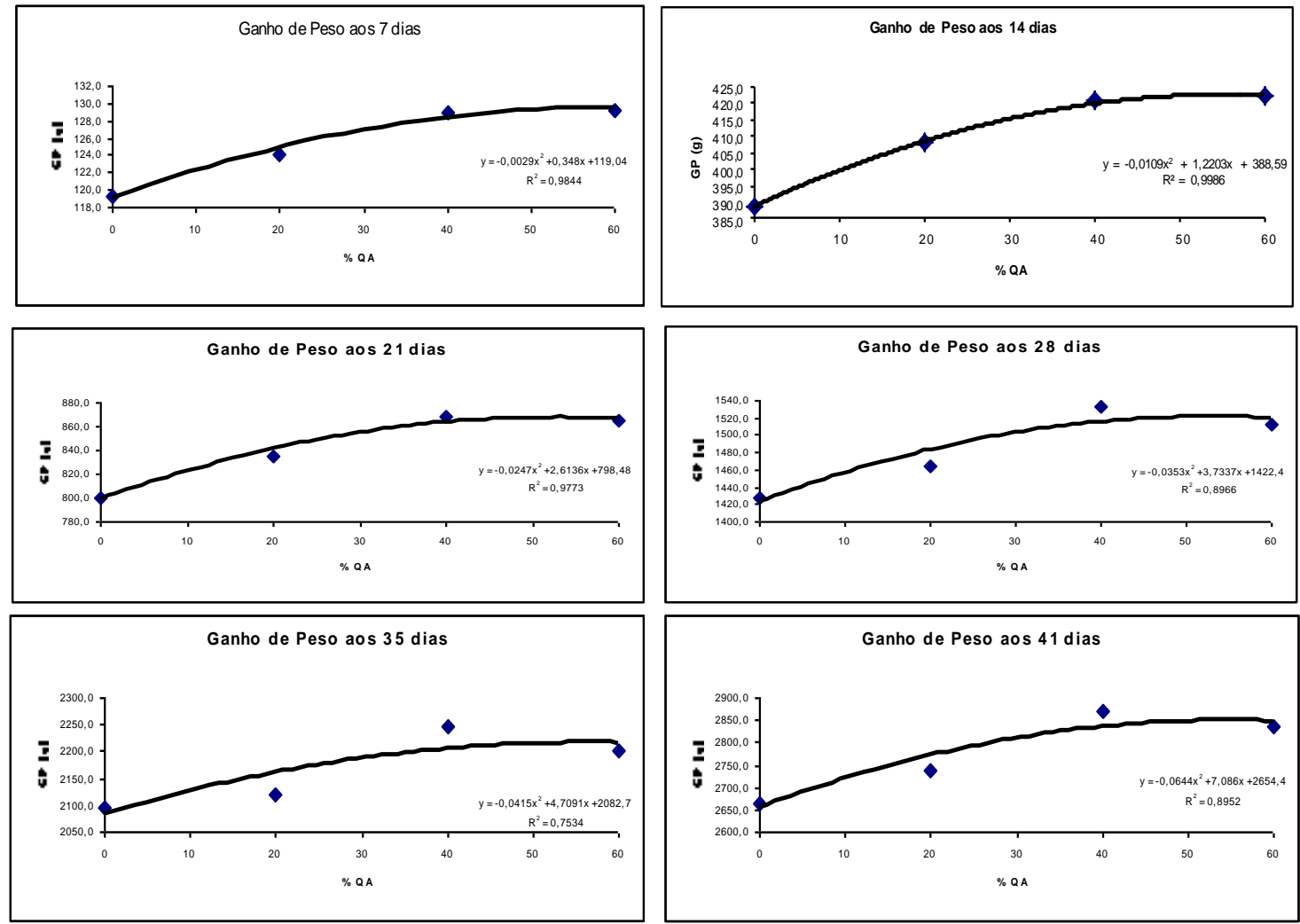

Figura 1 - Ganho de peso $(\mathrm{kg})$ de frangos de corte alimentados com dietas contendo diferentes níveis de quirera de arroz (QA).

Figure 1 - Weight gain $(\mathrm{kg})$ of broilers fed diets containing different levels of broken rice.
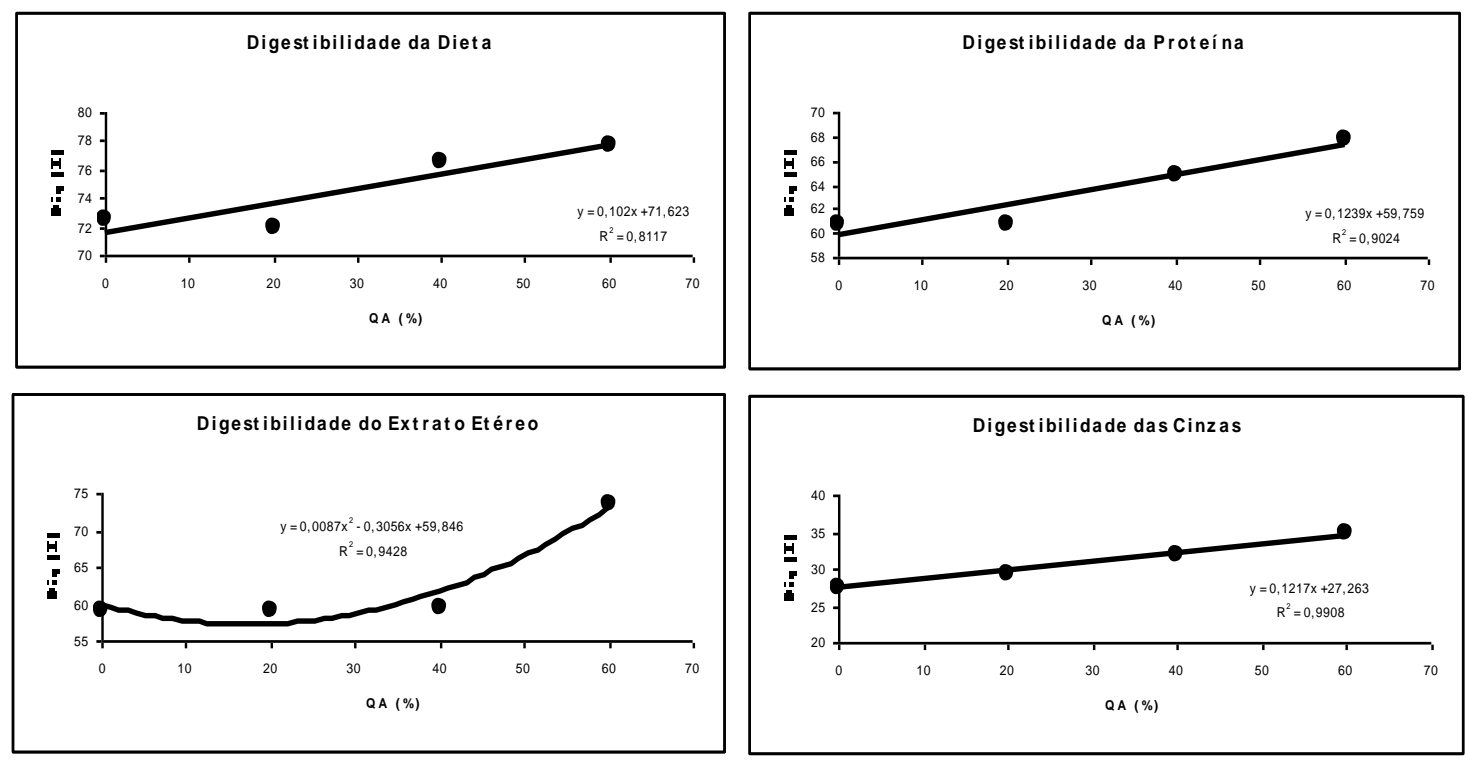

Figura 2 - Digestibilidade (\%) da dieta, da proteína bruta, do extrato etéreo e das cinzas em frangos de corte alimentados com dietas contendo diferentes níveis de quirera de arroz (QA).

Figure 2 - Digestibility (\%) of the diet, crude protein, ether extract and ash in broilers fed diets containing different levels of broken rice. 


\section{DISCUSSÃO}

Os resultados obtidos neste trabalho para o consumo de ração e a conversão alimentar concordam com os observados por Brum Jr. et al. (2007) que não verificaram diferenças no desempenho dos frangos até os 42 dias de idade alimentados com níveis de até 40\% de QA em substituição ao milho na dieta. Da mesma forma, Cancherini et al. (2008) não verificaram efeito da QA no desempenho de frangos de corte ao adicionar $22,5 \%$ até 21 dias de idade e $7,5 \%$ dos 22 aos 42 dias de idade. Trabalhando com os mesmos níveis de substituição do milho por QA em codornas de corte, Filgueira et al. (2014) também não encontraram prejuízos nas variáveis de desempenho, concluindo ser a QA um bom alimento substitutivo ao milho.

Neste trabalho o ganho de peso das aves apresentou efeito quadrático durante todo o período experimental, aumentando até o nível de $40 \%$ de QA. Cancherini et al. (2008) não notaram diferença significativa no ganho de peso de frangos de corte alimentados com dietas contendo milho ou $22,5 \%$ de QA em substituição ao milho, sugerindo ser possível a substituição.

Por outro lado, Ebling et al. (2015) obtiveram maior ganho de peso em frangos alimentados com dieta contendo arroz ao invés de milho até 21 dias. Após este período, no entanto, não houve mais diferença significativa para essa variável. Os autores acreditam que o incremento significativo no ganho de peso nas fases iniciais deva-se à melhor digestibilidade do amido do arroz em relação ao do milho.

Por sua vez, Oladunjoye; Ojebiyi (2010) encontraram piora na conversão alimentar e diminuição no ganho de peso de frangos de corte alimentados com $20 \%$ de arroz em suas dietas. Os mesmos autores atribuíram esses resultados ao alto teor de fibra presente no grão de arroz e que pode ter atingido níveis críticos para os animais com $20 \%$ de inclusão do mesmo, evidência não demonstrada no presente estudo.

Neste trabalho, verificou-se um aumento linear significativo na digestibilidade da dieta da proteína e das cinzas com o aumento do nível de QA na dieta dos frangos, até $60 \%$. Já a digestibilidade do extrato etéreo apresentou um 
comportamento quadrático, atingindo o ponto mínimo com 17,56\% de QA e depois aumentando até $60 \%$ de QA na dieta. Esses dados reforçam os obtidos por Apolônio et al. (2003), que verificaram digestibilidade de proteína e aminoácidos de $80 \%$ com QA na dieta em suínos.

Junqueira et al. (2009) caracterizaram a composição de farelo de arroz integral e de quirera de arroz e testaram seus usos nas dietas de frangos de corte, recomendando o mesmo. Porém, esses autores sugerem que se tenha atenção ao adicionar esses alimentos às dietas de frangos de corte, uma vez que contêm baixa energia e alta concentração de proteína bruta e aminoácidos digestíveis.

\section{CONCLUSÃO}

A quirera de arroz é um produto de qualidade que pode ser incorporado na dieta de frangos de corte em até $40 \%$ como substituição ao milho, aumentando a digestibilidade e o ganho de peso das aves.

\section{REFERÊNCIAS}

ABPA - ASSOCIAÇÃO BRASILEIRA DE PROTEÍNA ANIMAL. Relatório Anual ABPA 2018. Disponível em: http://abpa-br.com.br/storage/files/relatorio-anual2018.pdf. Acesso em: 26 ago 2018.

APOLÔNIO, L. R.; DONZELE, J. L.; OLIVEIRA, R. D.; SOUZA, A. D.; SILVA, F. D. O.; BÜNZEN, S. Digestibilidade ileal de aminoácidos de alguns alimentos, determinada pela técnica da cânula T simples com suínos. Revista Brasileira de Zootecnia, v.32, n.3, p.605-614. 2003. DOI: https://doi.org/10.1590/S151635982003000300012

BRUM JÚNIOR, B. S.; ZANELLA, I.; TOLEDO, G. S. P.; XAVIER, E. G.; VIEIRA, T. A.; GONÇALVES, E. C.; BRUM, H.; OLIVEIRA, J. L. S. Dietas para frangos de corte 
contendo quirera de arroz. Ciência Rural, v.37, n. 5, p.1423-1429. 2007. DOI: https://doi.org/10.1590/S0103-84782007000500032

CANCHERINI, L.C.; DUARTE, K.F.; JUNQUEIRA, O.M.; FILARDI, R. S.; LAURENTIZ, A. C.; ARAÚJO, L. F. Desempenho e rendimento de carcaça de frangos de corte alimentados com dietas contendo subprodutos do arroz formuladas com base nos conceitos de proteína bruta e ideal. Revista Brasileira de Zootecnia, v.37, n.4, p.616-623. 2008. DOI: https://doi.org/10.1590/S1516-35982008000400005

EBLING, P. D.; KeSSLER, A. M.; VILLANUEVA, A. P.; PONTALTI, G. C.; FARINA, G.; RIBEIRO, A. M. L. Rice and soy protein isolate in pre-starter diets for broilers. Poultry Science, v.94, n.11, p.2744-2752. 2015. DOI: https://doi.org/10.3382/ps/pev279

FIALHO, E.T.; BARBOSA, H.P.; LIMA, J.A.F.; SILVA, H.O.; CANTARELLI, V.S. Alimentos alternativos para suínos. 5.ed. Lavras: UFLA, 2005. 189p.

FILGUEIRA, T. M. B.; FREITAS, E. R.; QUEVEDO FILHO, I. B.; FERNANDES, D. R.; WATANABE, P. H.; DE OLIVEIRA, A. N. Corn replacement by broken rice in meat-type quail diets. Revista Brasileira de Ciência Avícola, v.16, n.4, p.345-350. 2014. DOI: https://doi.org/10.1590/1516-635×1604345-350

IBGE, Instituto Brasileiro de Geografia e Estatística, 2017. Disponível em: ftp://ttp.ibge.gov.br/Producao Agricola/Levantamento_Sistematico_da_Producao_Ag ricola_\%5Bmensal\%5D/Fasciculo/2017/Ispa_201701.pdf, Acesso em: 26 ago 2018.

JUNQUEIRA, O. M.; DUARTE, K. F.; CANCHERINI, L. C.; ARAÚJO, L. F.; OLIVEIRA, M. D.; GARCIA, E. A. Composição química, valores de energia metabolizável e aminoácidos digestíveis de subprodutos do arroz para frangos de corte. Ciência Rural, v.39, n.8, p.2497-2503. 2009. DOI: https://doi.org/10.1590/S0103-84782009005000197 
LIMBERGER, V. M.; DA SILVA, L. P.; EMANUELLI, T.; COMARELA, C. G.; PATIAS, L. D. Modificação química e física do amido de quirera de arroz para aproveitamento na indústria de alimentos. Química Nova, v.31, n.1, 84. 2008. DOI: https://doi.org/10.1590/S0100-40422008000100018

OLADUNJOYE, I. O.; OJEBIYI, O. O. Performance characteristics of broiler chicken (Gallus gallus) fed rice (Oriza sativa) bran with or without Roxazyme G2G. International Journal of Animal and Veterinary Advances, v.2, v.4, p.135-140. 2010.

OLIVEIRA, F. N.; RECH, R. R.; RISSI, D. R.; BARROS, R. R.; BARROS, C. S. Intoxicação em suínos pela ingestão de sementes de Aeschynomene indica (Leg. Papilionoideae). Pesquisa Veterinária Brasileira, v.25, n.3, p.135-142. 2005. DOI: https://doi.org/10.1590/S0100-736X2005000300003

RIZZO, P. V.; MENTEN, J. F. M.; RACANICCI, A. M. C.; TRALDI, A. B.; SILVA, C. S.; PEREIRA, P. W. Z. Extratos vegetais em dietas para frangos de corte. Revista Brasileira de Zootecnia, v.39, n.4, p.801-807. 2010. DOI: https://doi.org/10.1590/S1516-35982010000400015

ROSTAGNO, H.S.; ALBINO, L.F.T.; DONZELE, J.L.; GOMES, P.C.; OLIVEIRA, R.D.; LOPES, D.C.; FERREIRA, A.S.; BARRETO, S.L.T.; EUCLIDES, R.F. Composição de alimentos e exigências nutricionais. Tabelas brasileiras para aves e suínos. 2 ed. Viçosa: UFV, 2005. 186 p.

SILVA, R. F.; ASCHERI, J. L. R. Extrusão de quirera de arroz para uso como ingrediente alimentar. Brazilian Journal of Food Technology, v.12, n.3, p.190-199. 2009. DOI: $10.4260 / B J F T 2009800900012$

SILVA, D.J.; QUEIROZ, A.C. Análise de alimentos: métodos químicos e biológicos. 3.ed. Viçosa: UFV, 2002. 235p. 